\title{
The Requirement of Presynaptic Metabotropic Glutamate Receptors for the Maintenance of Locomotion
}

\author{
Michiko Takahashi ${ }^{1}$ and Simon Alford ${ }^{2}$ \\ 1Department of Physiology, Northwestern University Medical School, Chicago, Illinois 60611, and 2Department of \\ Biological Sciences, University of Illinois at Chicago, Chicago, Illinois 60607
}

\begin{abstract}
Spinal circuits known as central pattern generators maintain vertebrate locomotion. In the lamprey, the contralaterally alternating ventral root activity that defines this behavior is driven by ipsilateral glutamatergic excitation (Buchanan and Grillner, 1987) coupled with crossed glycinergic inhibition (Buchanan, 1982; Alford and Williams, 1989). These mechanisms are distributed throughout the spinal cord. Glutamatergic excitatory synapses activate AMPA and NMDA receptors known to be necessary for the maintenance of the locomotor rhythm. Less is known of the role and location of metabotropic glutamate receptors (mGluRs), although group I mGluRs enhance transmitter release at giant synapses in the lamprey spinal cord, whereas group II/III receptors may inhibit release. In this study we show that group I mGluR antagonists block fictive locomotion, a neural correlate of locomotion, by acting at the presynaptic terminal. Under physiological conditions, synaptically re-
\end{abstract}

leased glutamate activates presynaptic group I mGluRs (autoreceptors) during the repetitive activation of glutamatergic terminals. The resulting rise in $\left[\mathrm{Ca}^{2+}\right]_{i}$ caused by the release from presynaptic intracellular stores is coincident with an enhancement of synaptic transmission. Thus, blocking mGluRs reduces glutamate release during the repetitive activity that is characteristic of locomotion, leading to the arrest of locomotor activity. We found the effects of group I mGluRs on locomotion to be inconsistent with a postsynaptic effect on the central pattern generator. Consequently, the activation of metabotropic glutamate autoreceptors is necessary to maintain rhythmic motor output. Our results demonstrate the role of presynaptic mGluRs in the physiological control of movement for the first time.

Key words: neurotransmitter release; fictive locomotion; glutamate; lamprey; central pattern generator; presynaptic
Presynaptic receptors modulate transmitter release. They may alter $\mathrm{Ca}^{2+}$ channel gating by the action of a G-protein $\mathrm{G} \beta \gamma$ subunit (Dunlap and Fischbach, 1978; Herlitze et al., 1996; Ikeda, 1996; Zhang et al., 1996; De Waard et al., 1997) or through diff usible second messengers (Bernheim et al., 1991; Hille, 1992). Receptor-coupled $\mathrm{K}^{+}$channels are directly gated by $\mathrm{G} \beta \gamma$ subunits (Logothetis et al., 1987; Reuveny et al., 1994), and G-proteins may directly interfere with components of the soluble $N$-ethylmaleimide-sensitive factor attachment protein receptor (SNARE) complex that is responsible for vesicle fusion (Silinsky, 1984; Jarvis et al., 2000; Blackmer et al., 2001; Takahashi et al., 2001). G-proteins also alter axonal $\left[\mathrm{Ca}^{2+}\right]_{\mathrm{i}}$ by modulating its release from internal stores (Peng, 1996; Cochilla and Alford, 1998; Schwartz and Alford, 2000). In addition, phospholipase-Ccoupled receptors enhance neurotransmitter release either by acting directly through diacylglycerol binding to the SNARE complex (Lackner et al., 1999) or less directly through activation of a protein kinase (Evans et al., 2001).

In the lamprey spinal cord a number of presynaptic receptors have been identified. These include three metabotropic glutamate

Received May 16, 2001; revised Jan. 15, 2002; accepted Jan. 24, 2002.

This work was supported by National Institute of Neurological Disorders and Stroke Grant NS31713 (S.A.) and National Science Foundation Grant IBN 0094444 (S.A.) and by a Wellcome Traveling Prize Fellowship (M.T.). We thank Nigel Emptage, Heidi Hamm, Trillium Blackmer, Don McCrimmon, and Traverse Slater for their helpful comments on this manuscript and for many helpful discussions.

Correspondence should be addressed to Dr. Simon Alford, Department of Biological Sciences, University of Illinois at Chicago, 840 West Taylor Street, Chicago, IL 60607. E-mail: sta@uic.edu.

Dr. Takahashi's present address: Department of Physiology, University College London, Gower Street, London WC1E 6BT, UK.

Copyright (C) 2002 Society for Neuroscience $0270-6474 / 02 / 223692-08 \$ 15.00 / 0$ receptors (mGluRs) (Cochilla and Alford, 1998; Krieger et al., 1998), two GABA receptors (Alford et al., 1991), a 5-HT receptor (Buchanan and Grillner, 1995), and two ionotropic glutamate receptors (Cochilla and Alford, 1997). mGluRs are located throughout the CNS at presynaptic and postsynaptic sites (Koerner and Cotman, 1981; Forsythe and Clements, 1990; Conn and Pin, 1997; Finch and Augustine, 1998; Nakanishi et al., 1998). Pharmacology and gene deletion experiments have demonstrated that mGluRs have an important role in motor control and learning (Aiba et al., 1994; Conquet et al., 1994; Bortolotto et al., 1999; Kobayashi et al., 1999). However, despite a wealth of cell biological information about mGluRs, details of their role in a functional system are scarce. We have explored the role of mGluRs in the control of motor pattern generation.

Spinal central pattern generators (CPGs) maintain locomotion (Grillner and Dubuc, 1988; Jordan, 1998). In the lamprey this system is well characterized (Grillner et al., 1998). Activity of the CPG comprises ventral root bursting that alternates across the spinal cord (Cohen and Wallen, 1980) and is maintained by glutamatergic transmission between ipsilateral cells, so-called excitatory interneurons (EINs) (Buchanan and Grillner, 1987), coupled with contralateral glycinergic inhibition (Grillner and Wallen, 1980; Buchanan, 1982; Alford and Williams, 1989). The stability of these segmental oscillators is also maintained by activation of postsynaptic NMDA receptors and the bistable properties that they engender (Wallen and Grillner, 1987). The frequency of ventral-root bursting that underlies fictive locomotion is modulated by the action of mGluRs (Krieger et al., 1994, 1998, 2000). However, we understand little of what sculpts synaptic transmission and have only started to understand the impli- 


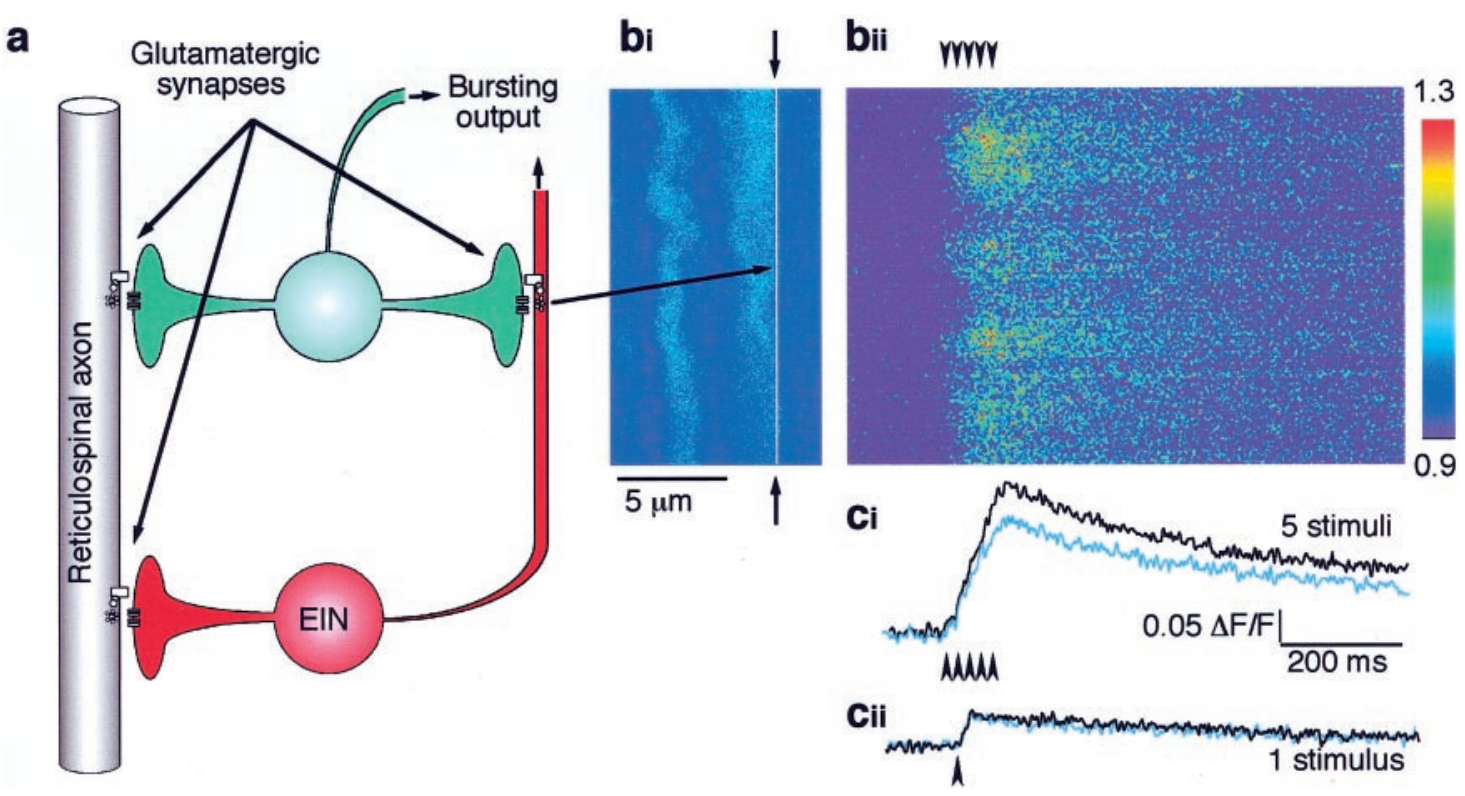

Figure 1. Activation of presynaptic mGluRs raises presynaptic $\left[\mathrm{Ca}^{2+}\right]_{\mathrm{i}} \cdot a$, Schematic diagram of the recorded network of neurons. Reticulospinal axons make en passant glutamatergic synaptic inputs to many ventral horn neurons ( green). EINs (red) also make glutamatergic synapses onto neurons in the ipsilateral spinal cord. Their axons project predominantly caudally and ipsilaterally. $b i$, EIN axons retrogradely labeled with the Ca ${ }^{2+}$-sensitive dye Oregon Green 488 BAPTA-1. Axons had ipsilateral cell bodies. bii, Image generated by scanning the laser over the location marked by the line and arrows in bi every $2 \mathrm{msec}$ while stimulating the axon extracellularly. Five $1 \mathrm{msec}$ stimuli $(50 \mathrm{~Hz})$ were given at the time marked by the arrowheads. The abscissa represents the distance along the axon; the ordinate represents time. The experiments were done in the presence of two ionotropic GluR antagonists, AP-5 $(50 \mu \mathrm{M})$ and CNQX $(10 \mu \mathrm{M})$. ci, The brightness value of all pixels at each time point were integrated to plot the fluorescence level taken from the line scan in bii in controls (black) and in the presence of the group I mGluR antagonist CPCCOEt (100 $\mu \mathrm{M}$, blue). cii, Integrated plot from the same axon as in bii with a single stimulus applied at the time indicated by an arrowhead in controls (black) and in CPCCOEt (blue). The time scale is the same for $b$ and $c$.

cations at the systems level, for example, in the creation of bursts of firing that are critical for the maintenance of locomotion (Parker and Grillner, 1999).

Here we demonstrate the role of the presynaptic mGluRs that enhance synaptic transmission in the maintenance of fictive locomotion.

\section{MATERIALS AND METHODS}

All experiments were performed at physiological temperature, $8-10^{\circ} \mathrm{C}$. Spinal cord preparation. Lamprey ammocoetes (Petromyzon marinus) were anesthetized with tricaine methyl sulfonate $(100 \mathrm{mg} / \mathrm{l})$ (MS222; Sigma, St. Louis, MO) and decapitated in accordance with our institutions' guidelines; sections of the spinal cord were then removed and maintained for recording as described previously (Cochilla and Alford, 1998). The meninx primitiva was also removed. The tissue was submerged in a flowing external solution $(1-2 \mathrm{ml} / \mathrm{min})$.

Calcium imaging. Fluorescence images were recorded with a Bio-Rad MRC600 (Hercules, CA) confocal microscope. A retrograde labeling technique was used to load a dextran amine conjugate of the $\mathrm{Ca}^{2+}$ sensitive dye Oregon Green 488 BAPTA-1 (Molecular Probes, Eugene, OR) onto the neurons (Cochilla and Alford, 1998). To load axons, the dye was applied to a caudal cut end of the spinal cord (for the motoneurons, to a cut ventral root), then the tissue was incubated overnight to allow the dye to be transported throughout. Putative EIN axons were identified by their small ipsilateral cell body and its fine twisted appearance and caudal projection. Activated presynaptic $\mathrm{Ca}^{2+}$ entry sites were found by scanning along the plasmalemma of axons while stimulating with a tungsten microelectrode. To detect a fast change in the presynaptic $\left[\mathrm{Ca}^{2+}\right]_{\mathrm{i}}$, images were collected at high speed by scanning a laser at $2 \mathrm{msec}$ intervals over a single line positioned at the axonal plasmalemma (Fig. $1 B i$, white line), while applying stimulation. To monitor a change in postsynaptic dendrites, two-dimensional images $(170 \times 251$ pixels $)$ were collected every $0.5 \mathrm{sec}$, and a train of stimulus $(25$ stimuli at $50 \mathrm{~Hz}$ ) was applied to the midline in the presence of 2-amino-5-phosphonopentanoate (AP-5; $50 \mu \mathrm{M}$ ) and 6-cyano-7-nitroquinoxaline-2,3-dione
(CNQX; $10 \mu \mathrm{M})$ after collecting three control images. Imaging data were analyzed using NIH Image software on a Macintosh computer. NIH Image was used to calculate the brightness value $(0-255$ per eight bits) for each pixel in a field of view. For each individual axon of interest, the brightness values were measured; after background subtraction, images were normalized to the baseline level of fluorescence to give $\Delta F / F$ values, for which the baseline value is 1 .

Photo-uncaging. Neurons were recorded under whole-cell conditions but under an Olympus BXW 50 (Olympus Optical, Tokyo, Japan) modified upright compound microscope. A UV laser targeting head (Prairie Technologies, Waunakee, WI) was inserted into the light path above the long wavelength imaging dichroic. This device enabled a UV source launched into the light path by a $35 \mu \mathrm{m}$ fiber optic line to be targeted to any location in the back plane of the objective lens (Olympus $40 \times$ numerical aperture 0.95 water immersion). The target point for the UV irradiation was marked by a red HeNe laser reflected into the eyepiece using the same targeting mirror. The UV laser $(300 \mu \mathrm{J}, 4 \mathrm{nsec}$ pulsed, 357 nm; LSI Inc., Franklin, MA) was triggered on demand with a TTL pulse. The amplitude of the pulse was controlled by an iris diaphragm in the UV fiber optic launch.

Electrophysiology. Putative motoneurons and interneurons, identified by their location in the tissue and by capacity transients in response to 10 $\mathrm{mV}$ voltage steps, were whole-cell-clamped using a patch-clamp amplifier (Axopatch 200A; Axon Instruments, Foster City, CA) with the blind technique. Patch electrodes were pulled using a horizontal micropipette puller (P-97 Micropipette Puller; Sutter Instruments, Novato, CA) to a tip resistance of 5-10 M $\Omega$ when filled with patch solution. Series resistance was continuously monitored by giving a $10 \mathrm{mV}$ voltage step before each episode; if the change exceeded $20 \%$, the cell was discarded. Intracellular recordings were made using an amplifier (Axoclamp 2A or 2B; Axon Instruments) with an electrode with a resistance of 30-60 M $\Omega$ when filled with $3 \mathrm{M}$ potassium methane sulfonate; cell types were identified by their location in the tissue and by capacity transients in response to $0.1 \mathrm{nA}$ current steps. Fictive locomotion was recorded using amplifiers (Axoclamp 2B and/or Axopatch 200B; Axon Instruments) 
after isolating the spinal cord by placing suction electrodes over the cut ventral roots (Cohen and Wallen, 1980).

Solutions. The patch pipette solution contained (in mM): 102.5 cesium methane sulfonate, $1 \mathrm{NaCl}, 1 \mathrm{MgCl}_{2}, 5$ EGTA, 5 HEPES, 3 ATP, and 0.3 GTP, $\mathrm{pH}$ adjusted to 7.2 with $\mathrm{CsOH}$. The external solution contained (in $\mathrm{mm}$ ): $100 \mathrm{NaCl}, 2.1 \mathrm{KCl}, 2.6 \mathrm{CaCl}_{2}, 1.8 \mathrm{MgCl}_{2}, 26 \mathrm{NaHCO}_{3}$, and 4 glucose, bubbled with $95 \% \mathrm{O}_{2}$ and $5 \% \mathrm{CO}_{2}$. Glutamate analogs were obtained from Tocris Cookson (Ballwin, MO); all other chemicals were from Sigma. Drugs were made as $1000 \times$ stock solution in aliquots for single use and kept in a freezer at $-20^{\circ} \mathrm{C}$; solutions with the final concentration of drugs were made fresh before each experiment. Drugs were applied to the superfusate.

\section{RESULTS}

Using giant synapses of the lamprey spinal cord, we previously identified a presynaptic group I mGluR that enhances glutamate release from the central terminals during trains of stimuli (Cochilla and Alford, 1998). This enhancement is mediated by an autoreceptor activated by the glutamate released from the presynaptic terminal; it is coincident with an mGluR-activated release of $\mathrm{Ca}^{2+}$ from presynaptic internal stores. The depolarizing and bursting phase of fictive locomotion is supported by the repetitive firing of EINs, a group of glutamatergic ventral horn neurons. These neurons release glutamate onto all other known classes of neurons, which are phasically active during fictive locomotion (Buchanan and Grillner, 1987) (Fig. 1a). The EINs possess small cell bodies (10-15 $\mu \mathrm{m}$ diameter) and their axons project ipsilaterally and caudally, making en passant synapses with postsynaptic neurons.

To see whether there are presynaptic group I mGluRs in the presynaptic terminals of EINs and whether they contribute to the presynaptic $\mathrm{Ca}^{2+}$ level, we monitored the presynaptic $\mathrm{Ca}^{2+}$ level of putative EINs by labeling their axons with the high-affinity $\mathrm{Ca}^{2+}$-sensitive dye Oregon Green 488 BAPTA-1 (Molecular Probes).

Stimuli were applied extracellularly to these axons either singly or as a train of five at $20 \mathrm{msec}$ intervals $(50 \mathrm{~Hz})$ in the presence of the ionotropic glutamate receptor blockers AP-5 $(50 \mu \mathrm{M})$ and CNQX $(10 \mu \mathrm{M})$. In both cases, the effect of a specific group I mGluR antagonist, 7-(hydroxyimino)cyclopropa[b]chromen-1acarboxylate ethyl ester (CPCCOEt; $100 \mu \mathrm{M}$ ) (Annoura et al., 1996; Litschig et al., 1999), was tested by comparing the peak amplitude of the evoked $\mathrm{Ca}^{2+}$ transient (Fig. 1b,c) with or without the antagonist. Responses to single stimuli were not significantly different from controls, whereas responses to repetitive stimulation were reduced to $88.9 \pm 1.8 \%$ of controls $(p<0.005$, paired two-tailed $t$ test; $n=5$ ).

In contrast to the small glutamatergic EIN axons, giant reticulospinal axons provide a readily accessible site for paired recording at a glutamatergic synapse. We used this synapse to look at the effect of blocking mGluRs on synaptic transmission. The amplitudes of EPSCs in ventral horn neurons, evoked by trains of presynaptic action potentials in the reticulospinal axons, were significantly reduced in the presence of CPCCOEt (Fig. 2) $(p<$ 0.05 in the third to fifth EPSC; $n=3$ ) (Cochilla and Alford, 1998). However, the first EPSC in the train was unaffected, supporting the hypothesis that group I mGluRs act as autoreceptors. To test whether CPCCOEt mediated its presynaptic effects at these giant axons in a manner similar to its effects at putative EIN presynaptic terminals, the presynaptic $\mathrm{Ca}^{2+}$ level was monitored in the reticulospinal axons labeled by the $\mathrm{Ca}^{2+}$ indicator. As above, stimuli were applied either singly or as a train of five at $20 \mathrm{msec}$ intervals $(50 \mathrm{~Hz})$; the effect of the application of CPCCOEt $(100 \mu \mathrm{M})$ on the peak amplitude of the evoked $\mathrm{Ca}^{2+}$
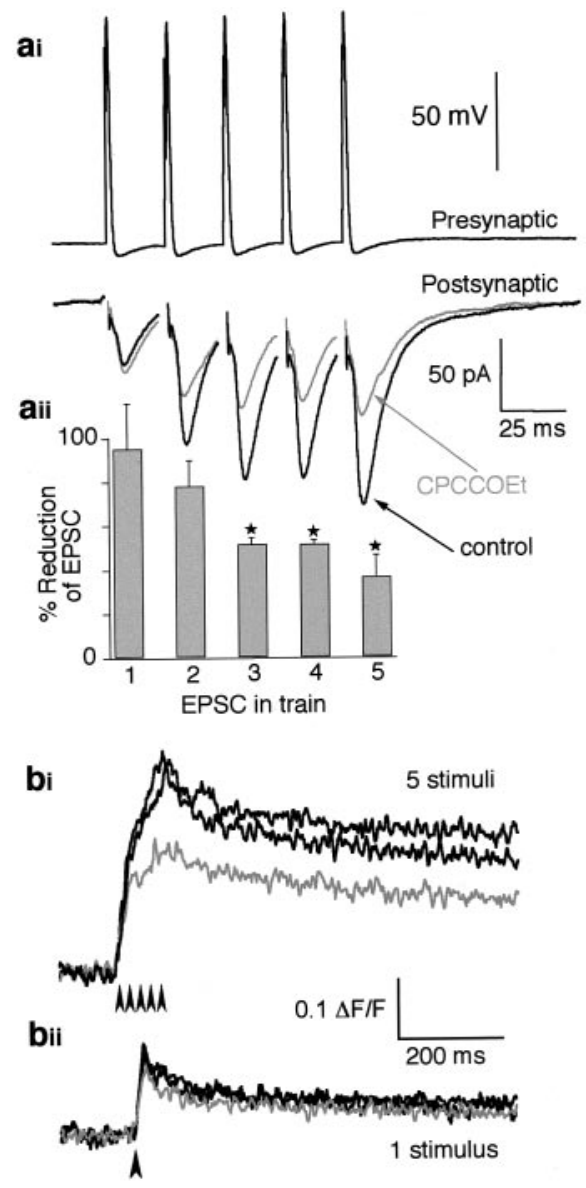

Figure 2. Activation of group I mGluRs increases transmitter release. ai, A paired recording from a presynaptic giant axon and a postsynaptic ventral horn neuron. Top, Intracellular recording from a reticulospinal axon with five action potentials evoked every $25 \mathrm{msec}$. Bottom, EPSCs evoked by the presynaptic action potentials above. The black trace shows the control response; the gray trace shows the response in CPCCOEt (100 $\mu \mathrm{M})$. aii, Histogram showing the pooled data of the EPSC amplitude reduction by CPCCOEt $(n=3)$ from paired recordings (as in $a i)$ for each EPSC in the train. Asterisks show where the reduction is significantly different from controls $(p<0.05)$. bi, Integrated $\mathrm{Ca}^{2+}$ imaging data taken from a reticulospinal axon. The response is to five stimuli (arrowheads) at $50 \mathrm{~Hz}$ applied to the axon. Data are shown before (black) and after (gray) the addition of CPCCOEt $(100 \mu \mathrm{M})$ and after washing the drug from the superfusate (black). bii, Data taken from the same axon as in $b i$, with a single stimulus (arrowhead). Data are shown before (black) and after (gray) application of CPCCOEt $(100 \mu \mathrm{M})$ and the washout (black).

transient was tested (Fig. 2b). Responses to single stimuli were reduced to $87.5 \pm 3.7 \%$ of controls $(p<0.01 ; n=10)$, and the responses to repetitive stimulation were reduced to $80.2 \pm 3.3 \%$ of controls ( $p<0.005 ; n=13$ ). CPCCOEt has a stronger effect on the amplitude of responses during repetitive stimulation than during single stimuli, which is consistent with the action of a presynaptic group I mGluR that enhances presynaptic $\mathrm{Ca}^{2+}$ concentrations after its activation as an autoreceptor (Cochilla and Alford, 1998).

These results suggest that group I mGluRs play a similar role in presynaptic $\mathrm{Ca}^{2+}$ homeostasis at the presynaptic terminals of small EIN axons and at giant reticulospinal axons. Thus, it is reasonable to hypothesize that this effect of group I mGluRs on synaptic release during the burst contributes to the modulation of the motor output of the spinal cord during locomotion. Fictive 


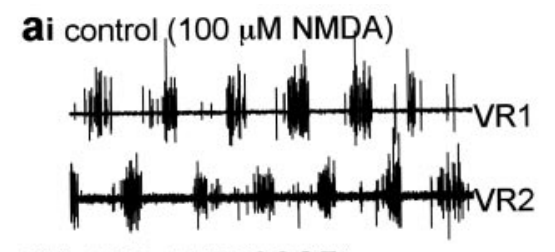

aii $+250 \mu \mathrm{M}$ CPCCOEt

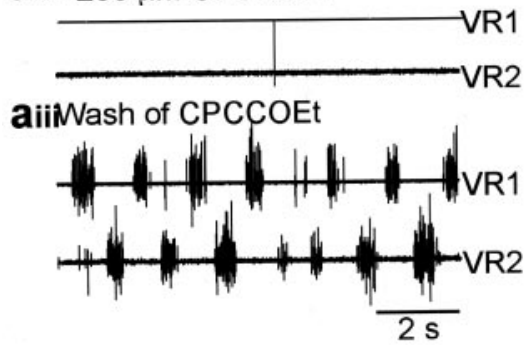

b

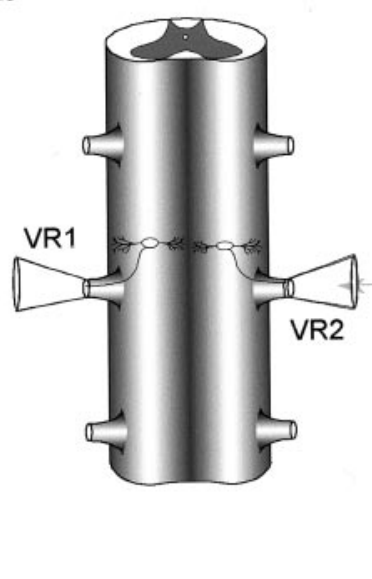

C

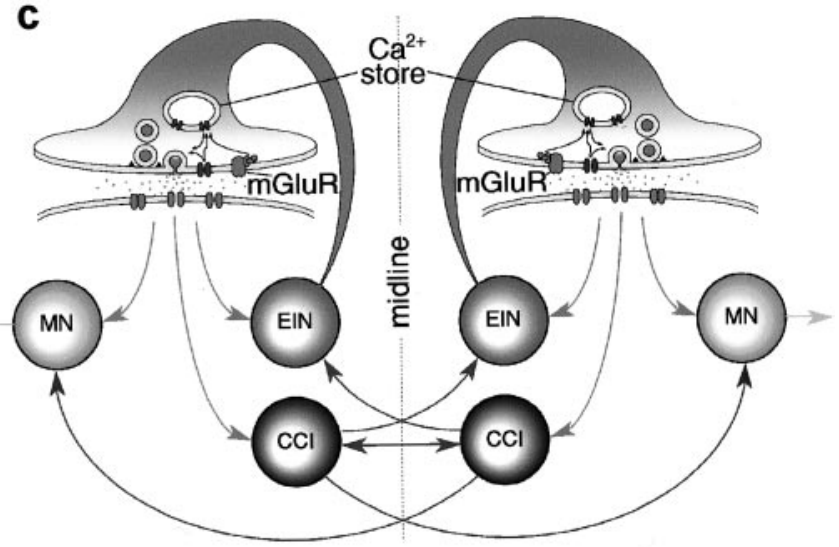

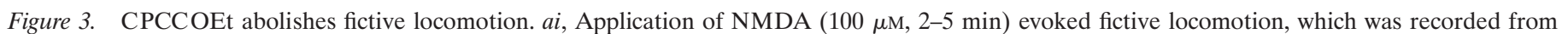

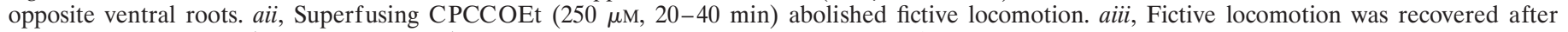

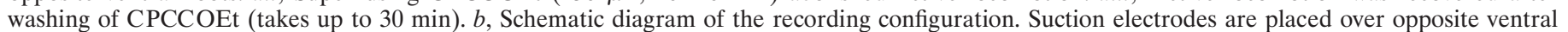

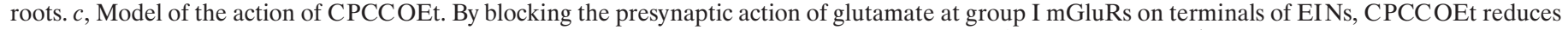

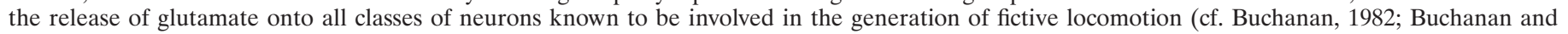
Grillner, 1987). $M N$, Motoneurons; CCI, crossed caudal interneurons.

locomotion, activated and sustained by the application of NMDA $(100 \mu \mathrm{M})$ to the superfusate (Brodin et al., 1985), was monitored from the isolated lamprey spinal cord by recording simultaneously from opposite ventral roots (Fig. $3 b$ ). The addition of CPCCOEt $(250 \mu \mathrm{M})$ to the superfusate reversibly abolished fictive locomotion (Fig. $3 a$ ) ( $n=7$ of 7 ). Swimming slowed over a washing period of up to $20 \mathrm{~min}$ before ceasing completely.

We have shown that presynaptic group I mGluRs enhance the synaptic release of glutamate and thus EPSC amplitudes during repetitive activation. Furthermore, the activation of these receptors is required for the maintenance of fictive locomotion. We propose that this autoreceptor-mediated facilitation of glutamate release is necessary to sustain the excitatory bursting of spinal interneurons that underlies fictive locomotion. In this scheme, during the burst, the presynaptic group I mGluRs are activated, augmenting synaptic glutamate release. Therefore, fictive locomotion, which requires the repetitive firing of EINs, is maintained by the enhanced release of glutamate. Then the loss of mGluR activation by blocking with CPCCOEt would not support sufficient glutamate release throughout the network to maintain fictive locomotion. This hypothesis is shown schematically in Figure $3 c$.

However, we must consider other possible actions of CPCCOEt in the maintenance of fictive locomotion. Alternative possibilities are (1) that blocking mGluRs modulates cellular mechanisms after the activation of NMDA receptors, particularly because group I mGluRs and NMDA receptor function converge on raising intracellular $\mathrm{Ca}^{2+}$ concentrations, or (2) that CPCCOEt acts on postsynaptic NMDA receptors, and thus abolishes fictive locomotion. Although it is clear that CPCCOEt application does not alter synaptic responses to single presynaptic stimuli (Fig. 2a) (Cochilla and Alford, 1998), the contribution of the NMDA receptors to the synaptic current that we recorded at $-70 \mathrm{mV}$ may not be significant. To examine these possibilities, fictive locomotion was induced independently of NMDA receptor activation, by the non-NMDA receptor agonist kainate $(15 \mu \mathrm{M})$ in the presence of the specific NMDA receptor antagonist AP-5 (50 $\mu \mathrm{M})$ (Brodin et al., 1985). The application of $250 \mu \mathrm{M}$ CPCCOEt

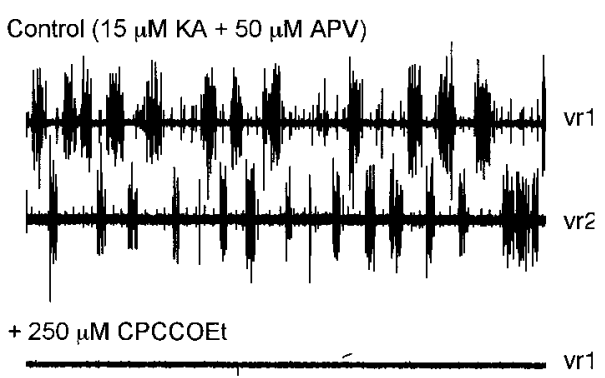

vr1

vre

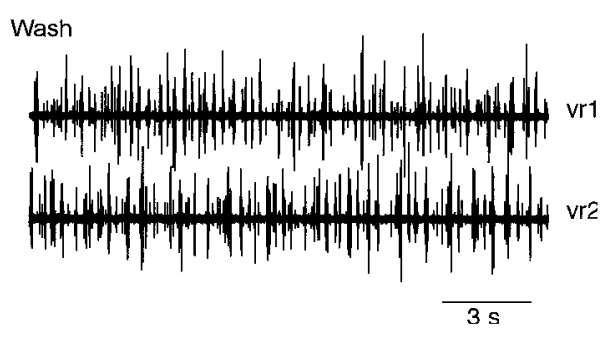

Figure 4. The effect of CPCCOEt is independent of postsynaptic NMDA receptor activation. Top, Kainate $(15 \mu \mathrm{M})$ evoked fictive locomotion in the presence of the NMDA receptor blocker AP-5 $(50 \mu \mathrm{M})$. Middle, bottom, This activity was reversibly abolished by CPCCOEt $(250 \mu \mathrm{M})$.

abolished the kainate-evoked ventral-root activity reversibly (Fig. 4) $(n=4$ of 4$)$, ruling out the possibility of mGluR action on postsynaptic NMDA receptors.

Group I mGluRs activate phospholipase $\mathrm{C}$ to produce inositol 1,4,5-triphosphate and release $\mathrm{Ca}^{2+}$ from intracellular stores (Nakanishi, 1994; Pin and Duvoisin, 1995). The neurons responsible for the maintenance of fictive locomotion undergo oscillations in membrane potential in response to the application of NMDA to the spinal cord (Sigvardt et al., 1985). This mechanism is thought to depend, in part, on fluctuations in postsynaptic intracellular $\mathrm{Ca}^{2+}$ concentrations (Wallen and Grillner, 1987). It is possible that the activation of postsynaptic group I mGluRs 


\section{ai control $(0.5 \mu \mathrm{M} T \mathrm{TX}+100 \mu \mathrm{M}$ NMDA $)$}

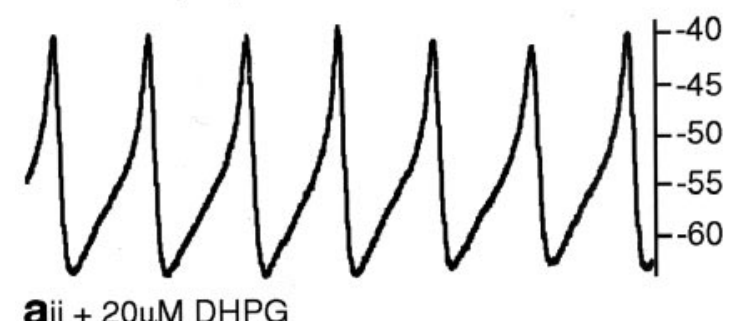

aii $+20 \mu M$ DHPG

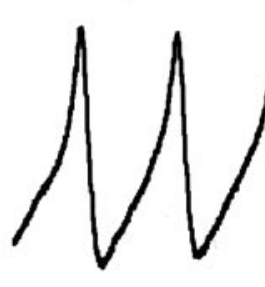

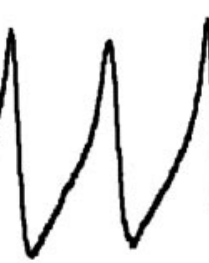

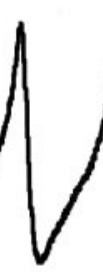

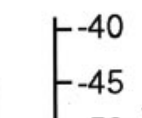

$-45$

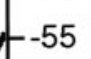

$-60$

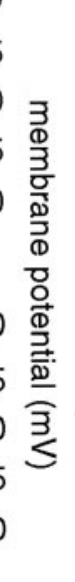

$1 \mathrm{~s}$

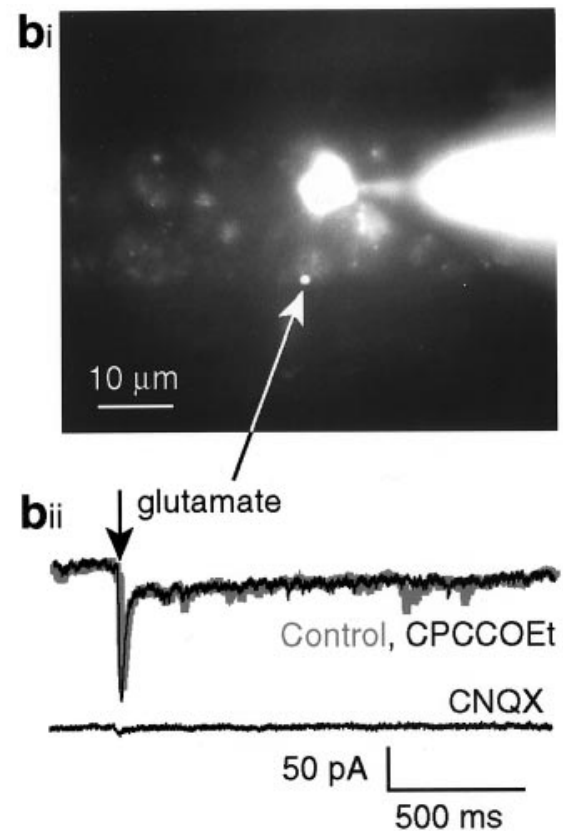

Figure 5. Group I mGluRs do not alter postsynaptic glutamatergic responses. ai, Oscillations recorded in a motoneuron under current-clamp conditions in the presence of NMDA $(100 \mu \mathrm{M})$ and TTX $(0.5 \mu \mathrm{M})$. aii, No effect was seen on these oscillations after the addition of the group I mGluR agonist DHPG $(20 \mu \mathrm{M})$ to the preparation. $b i$, A neuron held under whole-cell patch conditions. The neuron and patch electrode are clearly visible. The dendrite was identified as a fine line extending to the irradiation point marked by the small dot (arrow). bii. After the application of caged glutamate to the superfusate, a single UV laser pulse evoked an inward current in the neuron that was not affected by the application of CPCCOEt (200 $\mu \mathrm{M})$ but was blocked by the application of CNQX $(10 \mu \mathrm{M})$ to the superfusate. The responses shown are the average of four sequential responses evoked at 1 min intervals. The area of focused UV irradiation has a diameter of $\sim 4 \mu \mathrm{m}$ centered at the dot (arrow).

alters this membrane oscillation within postsynaptic neurons and thereby affects the maintenance of fictive locomotion. Indeed, Krieger et al. (2000) showed that activating postsynaptic group I mGluRs in isolated neurons by the application of their agonist 3,5-dihydroxyphenylglycine (DHPG; $50 \mu \mathrm{M}$ ) can modulate the NMDA-induced membrane oscillation (the frequency of oscillation was reduced), albeit with a great deal of variation between individual neurons. When we induced oscillations in spinal ventral horn neurons with NMDA $(100 \mu \mathrm{M})$ in the presence of TTX $(1 \mu \mathrm{M})$, DHPG $(20 \mu \mathrm{M}$; a dose with a profound presynaptic effect on glutamate release and $\mathrm{Ca}^{2+}$ ) (Cochilla and Alford, 1998) had a small and insignificant effect on oscillation frequency (mean oscillation frequency in controls was $1.8 \pm 0.1 \mathrm{~Hz}$ and that observed with DHPG was $1.9 \pm 0.2 \mathrm{~Hz} ; n=3$ ) (Fig. $5 a$ ). To achieve this, ventral horn neurons were recorded with sharp microelectrodes and the drugs were applied to the superfusate. The antagonist CPCCOEt itself has been reported to have no effect on NMDA receptor-mediated oscillations (Krieger et al., 2000). We confirmed this result $(n=2)$.

We wished to determine whether CPCCOEt might have any effect on glutamate-mediated responses applied specifically over the dendrites of lamprey ventral horn neurons. We used flash photolysis of caged glutamate to test this. Ventral horn neurons were recorded under whole-cell conditions. The electrode contained a long-wavelength indicator dye $(0.5 \mathrm{~mm}$ Oregon Green dextran; Molecular Probes) to locate the neuron under the fluorescence microscope. A pulsed UV laser was then targeted over the dendritic tree of the recorded neuron using a red HeNe laser imaged off the back of the UV dichroic mirror in the compound microscope. $\gamma$-L-glutamic acid $\gamma$ - $(\alpha$-carboxy-2-nitrobenzyl)ester, trifluorocetic acid salt caged glutamate $(100 \mu \mathrm{M})$ was then applied to the preparation through the superfusate and the UV laser was activated over the dendrite for a single pulse. This evoked a rapid inward current (Fig. 5b) that was unaffected by the application of CPCCOEt $(200 \mu \mathrm{M})$. However, the response was almost abolished by CNQX (10 $\mu \mathrm{M}$; a dose that will block both NMDA receptors and AMPA receptors in this preparation). These results indicate that activation of postsynaptic group I mGluRs is not necessary for the maintenance of NMDA receptor-dependent TTX-resistant oscillations and that it does not alter ionotropic glutamate receptor-mediated postsynaptic responses.

There are at least two subtypes of group I mGluRs (mGluR1 and mGluR5), each with splice variants. We sought to determine whether we could identify any pharmacological specificity of the group I mGluRs responsible for maintaining fictive locomotion. $(R, S)$-1-Aminoindan-1,5-dicarboxylic acid (AIDA) has been shown to be selective for mammalian mGluR1 over mGluR5 (Moroni et al., 1997). In contrast to CPCCOEt, AIDA $(500 \mu \mathrm{M})$ had no effect on the amplitude of the evoked presynaptic $\mathrm{Ca}^{2+}$ transient in the axons, whether in response to a single stimulation or to repetitive stimulation (five stimuli at $50 \mathrm{~Hz}$; response in AIDA was $99.2 \pm 1.4 \%$ of controls; $n=7$ ) (Fig. $6 a$ ). Nor did AIDA affect the evoked synaptic current recorded in postsynaptic neurons (Fig. 6b) (mean EPSC amplitude in AIDA was $96.4 \pm$ $3.4 \%$ of controls, $n=3$ ). AIDA also did not block fictive locomotion $(n=3)$ (Fig. $6 c$ ).

It remains possible that AIDA has no effect on lamprey mGluRs. To test this, we labeled postsynaptic motoneurons with a $\mathrm{Ca}^{2+}$-sensitive dye (Oregon Green 488 BAPTA-1; Molecular Probes) by applying the dextran conjugate of the dye to the ventral roots (see Materials and Methods) and examined the effect of AIDA on synaptically evoked postsynaptic $\mathrm{Ca}^{2+}$ transients (Fig. 7). A train of 25 stimuli $(50 \mathrm{~Hz})$ to the ventral medial tract synaptically evoked postsynaptic $\mathrm{Ca}^{2+}$ transients in mo- 

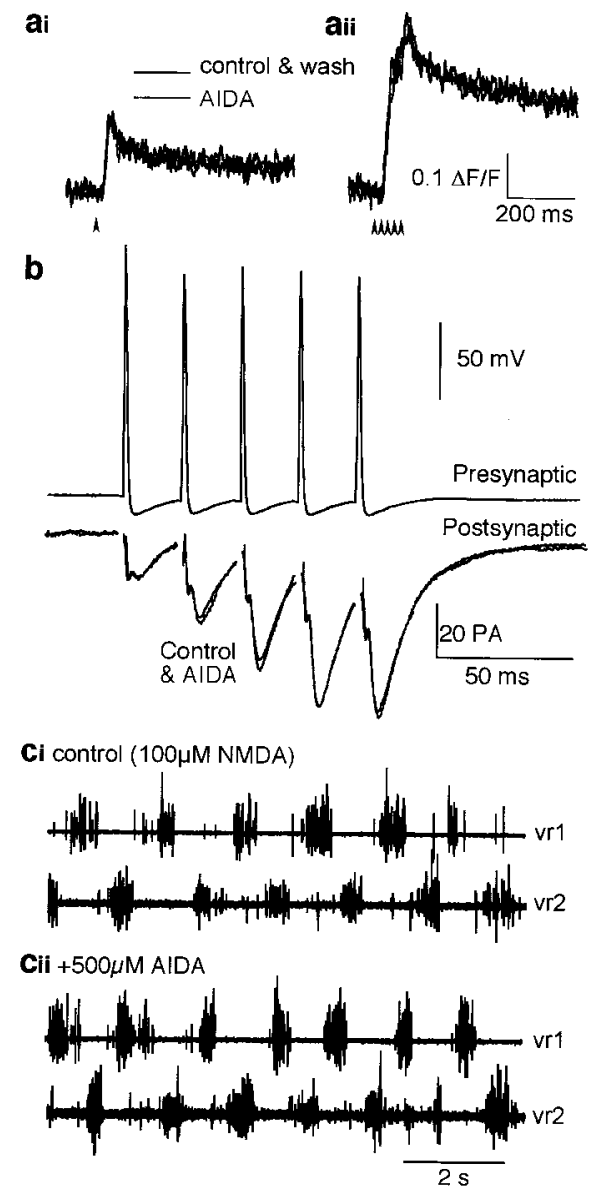

Figure 6. Application of the group I mGluR antagonist AIDA has no presynaptic effect. $a, \mathrm{Ca}^{2+}$ transients evoked in reticulospinal axons and imaged as for Figure 1. AIDA had no effect on the presynaptic $\mathrm{Ca}^{2+}$ response to a single stimulus (ai, arrowhead) or to five stimuli (arrowheads) at $50 \mathrm{~Hz}$ (aii). b, AIDA had no effect on transmitter release from a giant axon. A paired recording was made between a reticulospinal axon and a voltage-clamped ventral horn neuron. EPSCs evoked by repetitive stimulation of the axon (five action potentials at $50 \mathrm{~Hz}$ ) were unaffected by the application of AIDA $(500 \mu \mathrm{M})$. $c$, Fictive locomotion evoked by 100 $\mu \mathrm{M}$ NMDA ( $c i)$ was not affected by AIDA $(500 \mu \mathrm{M} ; c i i)$. Note that this is the same preparation shown in Figure 3, in which CPCCOEt abolished fictive locomotion.

toneuron dendrites. AIDA $(500 \mu \mathrm{M})$ reduced the amplitude of the postsynaptic $\mathrm{Ca}^{2+}$ transient (to $73 \pm 4 \%$ of controls; $n=3$; $p<0.05$ ) (Fig. 7b). This suggests that group I mGluRs are located postsynaptically and can be blocked with AIDA at concentrations that do not have presynaptic effects and do not alter fictive locomotion. Together, these results suggest that AIDA-sensitive group I mGluRs are found postsynaptically but that the effect of CPCCOEt on locomotion is primarily by a presynaptic mechanism. This is consistent with the hypothesis that presynaptic group I mGluRs are necessary for the maintenance of locomotion.

\section{DISCUSSION}

At vertebrate central synapses, the synaptic activation of presynaptic mGluRs may lead to either a reduction in (Burke and Hablitz, 1994; Krieger et al., 1994, 2000) or a facilitation of (Budd and Nicholls, 1995; Dong et al., 1996) transmitter release. In the lamprey, we have shown previously that the activation of group I mGluRs (Cochilla and Alford, 1998; Schwartz and Alford, 2000)
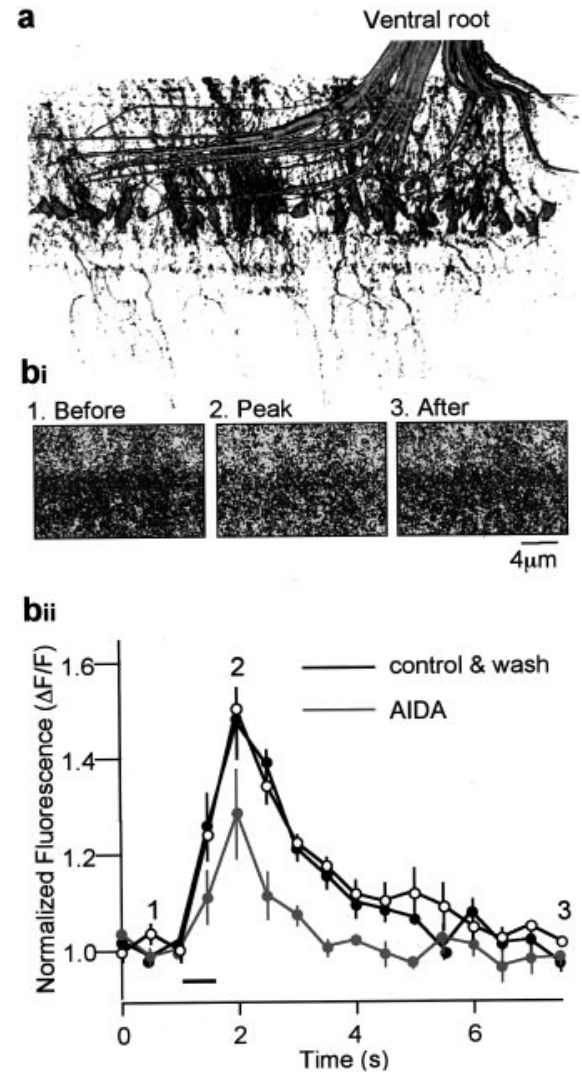

Figure 7. AIDA suppresses the postsynaptic $\mathrm{Ca}^{2+}$ transient. $a$, Dye fill of a spinal ventral root. Dextran-conjugated dye applied to the cut ventral root retrogradely labeled the axons, cell bodies, and dendrites of motoneurons. This image is a three-dimensional reconstruction of the segment of fixed tissue to demonstrate that the staining is specific to motoneurons and their dendrites. $b, \mathrm{Ca}^{2+}$ transients were evoked in the dye-filled motoneuron dendrites. Stimulation of the medial spinal tracts activates reticulospinal axons and evokes synaptic potentials, thus causing an increase of $\left[\mathrm{Ca}^{2+}\right]_{\mathrm{i}}$ in the motoneurons $(\mathrm{bi})$. These axons were stimulated at $50 \mathrm{~Hz}$ (25 stimuli) at the time indicated by the bar in bii. This transient was plotted, and the effect of the application of AIDA $(500 \mu \mathrm{M})$ is shown in gray.

can lead to an increase in both the spontaneous and the evoked release of glutamate coincident with a release of $\mathrm{Ca}^{2+}$ from presynaptic internal stores. In particular, this facilitation in lamprey synapses is mediated by an mluR acting as an autoreceptor. In this case, glutamate released from the affected terminal has been shown to augment additional release during repetitive activation of the terminal (Cochilla and Alford, 1998). Here we report, as a consequence, that the group I mGluR antagonist CPCCOEt acts at presynaptic glutamatergic terminals to reduce the efficacy of excitatory synaptic transmission during trains of presynaptic action potentials. Application of CPCCOEt to the spinal cord also abolishes fictive locomotion. This effect is consistent with an autoreceptor-mediated synaptic facilitation activated during the repetitive firing of excitatory neurons that is observed during fictive locomotion (Cohen and Wallen, 1980; Buchanan and Grillner, 1987). There are some quantitative differences in the effects on single or multiple responses, leaving open the possibility that group I mGluRs may also be found at axo-axonic synapses that are present on reticulospinal terminals (Cochilla and Alford, 1997, 1999), whereas a lack of effect of CPCCOEt on postsynaptic glutamate responses limits the postsynaptic role of these receptors. We propose that this facili- 
tation of glutamate release is necessary to support the spinal CPG during fictive locomotion.

It is also possible that there is a postsynaptic site at which group I mGluRs are required to maintain locomotion. Indeed, Krieger et al. (2000) have shown that group I mGluRs enhance postsynaptically recorded NMDA-mediated responses. However, a presynaptic site of action of CPCCOEt on fictive locomotion is favored by four results. First, kainate-induced fictive locomotion, evoked during the blockade of NMDA receptors, was abolished by CPCCOEt. Second, the response of the postsynaptic ventral horn neuron to glutamate and to NMDA-induced oscillatory activity, which is dependent on postsynaptic $\left[\mathrm{Ca}^{2+}\right]_{\mathrm{i}}$ and independent of network activity, was not affected by the application of CPCCOEt. Third, AIDA, a selective inhibitor of mGluR1, can significantly reduce postsynaptic $\mathrm{Ca}^{2+}$ transients evoked by the synaptic release of glutamate, but it does not affect either presynaptic $\mathrm{Ca}^{2+}$ transients or fictive locomotion. Finally, the effect of DHPG, a selective group I mGluR agonist, on NMDA-induced neuronal oscillations was opposite in sign to its effect on swimming (Krieger et al., 1998, 2000). Thus, we conclude that the augmentation of the glutamate release mediated by presynaptic group I mGluRs enhances the endogenous release of glutamate during fictive locomotion.

We have shown that presynaptic glutamatergic terminals, at both putative EIN axons and giant reticulospinal axons, possess mGluR autoreceptors that enhance $\mathrm{Ca}^{2+}$ concentrations in the presynaptic terminal during bursting activity. Our previous studies (Cochilla and Alford, 1998; Schwartz and Alford, 2000), combined with the present work, show that this release of $\mathrm{Ca}^{2+}$ from presynaptic internal stores is accompanied by an enhancement of glutamate release during bursts of presynaptic action potentials (Cochilla and Alford, 1998). EINs play a critical role in the maintenance of locomotion generated by the CPGs of the spinal cord. Without the phasic release of glutamate from these neurons, bursting activity cannot be maintained (Buchanan and Grillner, 1987; Lansner et al., 1998). Our data demonstrate that the application of the group I mGluR antagonist CPCCOEt abolishes fictive locomotion without preventing the postsynaptic activation of either AMPA or NMDA receptors.

The augmentation of transmitter release mediated by the activation of presynaptic mGluRs has now been demonstrated in many regions of the nervous system, ranging from the neuromuscular junction (Zhang et al., 1999) to the cerebral cortex (Moroni et al., 1998). In all regions of the nervous system the transmission of frequency-encoded information by repetitive firing of the neurons involved is considered a fundamental property. We have demonstrated an mGluR-mediated increase in transmitter release and a disruption of network activity by blocking mGluRs. We suggest that, as a probable mechanism, autoreceptor-mediated augmentation of transmitter release is required for systems-level physiological activity. This function may be thematic and important in both the physiology and pathology (Bianchi and Wong, 1995; Merlin et al., 1995, 1999) of the nervous system.

\section{REFERENCES}

Aiba A, Kano M, Chen C, Stanton ME, Fox GD, Herrup K, Zwingman TA, Tonegawa S (1994) Deficient cerebellar long-term depression and impaired motor learning in mGluR1 mutant mice. Cell 79:377-388.

Alford S, Williams TL (1989) Endogenous activation of glycine and NMDA receptors in lamprey spinal cord during fictive locomotion. J Neurosci 9:2792-2800.

Alford S, Christenson J, Grillner S (1991) Presynaptic GABA $\mathrm{A}_{\mathrm{A}}$ and $\mathrm{GABA}_{\mathrm{B}}$ receptor-mediated phasic modulation in axons of spinal motor interneurons. Eur J Neurosci 3:107-117.
Annoura H, Fukunaga A, Uesugi M, Tatsuaka T, Horikawa Y (1996) A novel class of antagonists for metabotropic glutamate receptors, 7 (hydroxyimino) cyclopropa[b]chromen-1a-carboxylates. Bioorg Med Chem Lett 6:763.

Bernheim L, Beech DJ, Hille B (1991) A diffusible second messenger mediates one of the pathways coupling receptors to calcium channels in rat sympathetic neurons. Neuron 6:859-867.

Bianchi R, Wong RK (1995) Excitatory synaptic potentials dependent on metabotropic glutamate receptor activation in guinea-pig hippocampal pyramidal cells. J Physiol (Lond) 487:663-676.

Blackmer T, Larsen E, Takahashi M, Martin TFJ, Alford S, Hamm HE (2001) $\mathrm{G}$ protein $\beta \gamma$ subunit-mediated presynaptic inhibition: regulation of exocytotic fusion downstream of $\mathrm{Ca}^{2+}$ entry. Science 292:293-297.

Bortolotto ZA, Fitzjohn SM, Collingridge GL (1999) Roles of metabotropic glutamate receptors in LTP and LTD in the hippocampus. Curr Opin Neurobiol 9:299-304.

Brodin L, Grillner S, Rovainen CM (1985) N-Methyl-D-aspartate (NMDA), kainate and quisqualate receptors and the generation of fictive locomotion in the lamprey spinal cord. Brain Res 325:302-306.

Buchanan JT (1982) Identification of interneurons with contralateral, caudal axons in the lamprey spinal cord: synaptic interactions and morphology. J Neurophysiol 47:961-975.

Buchanan JT, Grillner S (1987) Newly identified "glutamate interneurons" and their role in locomotion in the lamprey spinal cord. Science 236:312-314.

Buchanan JT, Grillner S (1995) 5-Hydroxytryptamine depresses reticulospinal excitatory postsynaptic potentials in motoneurons of the lamprey. Neurosci Lett 122:71-74.

Budd DC, Nicholls DG (1995) Protein kinase C-mediated suppression of the presynaptic adenosine $\mathrm{A}_{1}$ receptor by a facilitatory metabotropic glutamate receptor. J Neurochem 65:615-621.

Burke JP, Hablitz JJ (1994) Presynaptic depression of synaptic transmission mediated by activation of metabotropic glutamate receptors in rat neocortex. J Neurosci 14:5120-5130.

Cochilla AJ, Alford S (1997) Glutamate receptor-mediated synaptic excitation in axons of the lamprey. J Physiol (Lond) 499:443-457.

Cochilla AJ, Alford S (1998) Metabotropic glutamate receptormediated control of neurotransmitter release. Neuron 20:1007-1016.

Cochilla AJ, Alford S (1999) NMDA receptor-mediated control of presynaptic calcium and neurotransmitter release. J Neurosci 19:193-205.

Cohen AH, Wallen P (1980) The neuronal correlate of locomotion in fish: "fictive swimming" induced in an in vitro preparation of the lamprey spinal cord. Exp Brain Res 41:11-18.

Conn PJ, Pin JP (1997) Pharmacology and functions of metabotropic glutamate receptors. Annu Rev Pharmacol Toxicol 37:205-237.

Conquet F, Bashir ZI, Davies CH, Daniel H, Ferraguti F, Bordi F, Franz-Bacon K, Reggiani A, Matarese V, Conde F, Collingridge GL, Crepel F (1994) Motor deficit and impairment of synaptic plasticity in mice lacking mGluR1. Nature 372:237-243.

De Waard M, Liu H, Walker D, Scott VE, Gurnett CA, Campbell KP (1997) Direct binding of G-protein beta gamma complex to voltagedependent calcium channels. Nature 385:446-450.

Dong X-W, Morin D, Feldman JL (1996) Multiple actions of $1 S, 3 R$ ACPD in modulating endogenous synaptic transmission to spinal respiratory motoneurons. J Neurosci 16:4971-4982.

Dunlap K, Fischbach GD (1978) Neurotransmitters decrease the calcium component of sensory neurone action potentials. Nature 276:837-839.

Evans DD, Jones RS, Woodhall G (2001) Differential actions of PKA and PKC in the regulation of glutamate release by group III mGluRs in the entorhinal cortex. J Neurophysiol 85:571-579.

Finch EA, Augustine GJ (1998) Local calcium signalling by inositol1,4,5-trisphosphate in Purkinje cell dendrites. Nature 396:753-756.

Forsythe ID, Clements JD (1990) Presynaptic glutamate receptors depress excitatory monosynaptic transmission between mouse hippocampal neurones. J Physiol (Lond) 429:1-16.

Grillner S, Dubuc R (1988) Control of locomotion in vertebrates: spinal and supraspinal mechanisms. Adv Neurol 47:425-453.

Grillner S, Wallen P (1980) Does the central pattern generation for locomotion in lamprey depend on glycine inhibition? Acta Physiol Scand 110:103-105.

Grillner S, Ekeberg O, El Manira A, Lansner A, Parker D, Tegner J, Wallen P (1998) Intrinsic function of a neuronal network: a vertebrate central pattern generator. Brain Res Brain Res Rev 26:184-197.

Herlitze S, Garcia DE, Mackie K, Hille B, Scheuer T, Catterall WA (1996) Modulation of $\mathrm{Ca} 2+$ channels by G-protein beta gamma subunits. Nature 380:258-262.

Hille B (1992) G protein-coupled mechanisms and nervous signaling. Neuron 9:187-195.

Ikeda SR (1996) Voltage-dependent modulation of N-type calcium channels by G-protein beta gamma subunits. Nature 380:255-258.

Jarvis SE, Magga JM, Beedle AM, Braun JE, Zamponi GW (2000) G protein modulation of N-type calcium channels is facilitated by physical interactions between syntaxin $1 \mathrm{~A}$ and $\mathrm{G} \beta \gamma$. J Biol Chem 275:6388-6394. 
Jordan LM (1998) Initiation of locomotion in mammals. Ann N Y Acad Sci 860:83-93.

Kobayashi K, Manabe T, Takahashi T (1999) Calcium-dependent mechanisms involved in presynaptic long-term depression at the hippocampal mossy fibre-CA3 synapse. Eur J Neurosci 11:1633-1638.

Koerner JF, Cotman CW (1981) Micromolar L-2-amino-4-phosphonobutyric acid selectively inhibits perforant path synapses from lateral entorhinal cortex. Brain Res 216:192-198.

Krieger P, Tegner J, el Manira A, Grillner S (1994) Effects of metabotropic glutamate receptor activation on the cellular and network level in the lamprey spinal cord. NeuroReport 5:1760-1762.

Krieger P, Grillner S, El Manira A (1998) Endogenous activation of metabotropic glutamate receptors contributes to burst frequency regulation in the lamprey locomotor network. Eur J Neurosci 10:3333-3342.

Krieger P, Hellgren-Kotaleski J, Kettunen P, El Manira AJ (2000) Interaction between metabotropic and ionotropic glutamate receptors regulates neuronal network activity. J Neurosci 20:5382-5391.

Lackner MR, Nurrish SJ, Kaplan JM (1999) Facilitation of synaptic transmission by EGL-30 Gq $\alpha$ and EGL-8 PLC $\beta$ : DAG binding to UNC-13 is required to stimulate acetylcholine release. Neuron 24:335-346.

Lansner A, Kotaleski JH, Grillner S (1998) Modeling of the spinal neuronal circuitry underlying locomotion in a lower vertebrate. Ann NY Acad Sci 860:239-249.

Litschig S, Gasparini F, Rueegg D, Stoehr N, Flor PJ, Vranesic I, Prezeau L, Pin JP, Thomsen C, Kuhn R (1999) CPCCOEt, a noncompetitive metabotropic glutamate receptor 1 antagonist, inhibits receptor signaling without affecting glutamate binding. Mol Pharmacol 55:453-461.

Logothetis DE, Kurachi Y, Galper J, Neer EJ, Clapham DE (1987) The beta gamma subunits of GTP-binding proteins activate the muscarinic $\mathrm{K}+$ channel in heart. Nature 325:321-326.

Merlin LR (1999) Group I mGluR-mediated silent induction of longlasting epileptiform discharges. J Neurophysiol 82:1078-1081.

Merlin LR, Taylor GW, Wong RK (1995) Role of metabotropic glutamate receptor subtypes in the patterning of epileptiform activities in vitro. J Neurophysiol 74:896-900.

Moroni F, Lombardi G, Thomsen C, Leonardi P, Attucci S, Peruginelli F, Torregrossa SA, Pellegrini-Giampietro DE, Luneia R, Pellicciari R (1997) Pharmacological characterization of 1-aminoindan-1,5dicarboxylic acid, a potent mGluR1 antagonist. J Pharmacol Exp Ther 281:721-729.

Moroni F, Cozzi A, Lombardi G, Sourtcheva S, Leonardi P, Carfi M,
Pellicciari R (1998) Presynaptic mGlu1 type receptors potentiate transmitter output in the rat cortex. Eur J Pharmacol 347:189-195.

Nakanishi S (1994) The molecular diversity of glutamate receptors. Prog Clin Biol Res 390:85-98.

Nakanishi S, Nakajima Y, Masu M, Ueda Y, Nakahara K, Watanabe D, Yamaguchi S, Kawabata S, Okada M (1998) Glutamate receptors: brain function and signal transduction. Brain Res Brain Res Rev 26:230-235.

Parker D, Grillner S (1999) Activity-dependent metaplasticity of inhibitory and excitatory synaptic transmission in the lamprey spinal cord locomotor network. J Neurosci 19:1647-1656.

Peng Y (1996) Ryanodine-sensitive component of calcium transients evoked by nerve firing at presynaptic nerve terminals. J Neurosci 16:6703-6712.

Pin JP, Duvoisin R (1995) The metabotropic glutamate receptors: structure and functions. Neuropharmacology 34:1-26.

Reuveny E, Slesinger PA, Inglese J, Morales JM, Iniguez-Lluhi JA, Lefkowitz RJ, Bourne HR, Jan YN, Jan LY (1994) Activation of the cloned muscarinic potassium channel by $\mathrm{G}$ protein $\beta \gamma$ subunits. Nature 370:143-146.

Schwartz NE, Alford S (2000) Physiological activation of presynaptic metabotropic glutamate receptors increases intracellular calcium and glutamate release. J Neurophysiol 84:415-427.

Sigvardt KA, Grillner S, Wallen P, Van Dongen PA (1985) Activation of NMDA receptors elicits fictive locomotion and bistable membrane properties in the lamprey spinal cord. Brain Res 336:390-395.

Silinsky EM (1984) On the mechanism by which adenosine receptor activation inhibits the release of acetylcholine from motor nerve endings. J Physiol (Lond) 346:243-256.

Takahashi M, Freed R, Blackmer T, Alford S (2001) Calcium influx independent depression of transmitter release by 5-HT at lamprey spinal cord synapses. J Physiol (Lond) 532:323-336.

Wallen P, Grillner S (1987) N-methyl-D-aspartate receptor-induced, inherent oscillatory activity in neurons active during fictive locomotion in the lamprey. J Neurosci 7:2745-2755.

Zhang D, Kuromi H, Kidokoro Y (1999) Activation of metabotropic glutamate receptors enhances synaptic transmission at the Drosophila neuromuscular junction. Neuropharmacology 38:645-657.

Zhang JF, Ellinor PT, Aldrich RW, Tsien RW (1996) Multiple structural elements in voltage-dependent $\mathrm{Ca}^{2+}$ channels support their inhibition by G proteins. Neuron 17:991-1003. 